\title{
Marta Zafrilla y LA PRIMERA EdUCACión LiteraRia: LAS CAMISETAS NO SOMOS SERVILLETAS
}

\author{
Paloma Rosauro Moragues \\ Graduada en Educación Primaria
}

Desde que en el año 2006, con tan solo veinticuatro años, la escritora murciana Marta Zafrilla Díaz (Murcia, 1982) fuera merecedora del premio Autora Revelación de la Región de Murcia y, tan solo un año después, del premio Angular concedido por la editorial SM a nivel nacional, su trayectoria ha sido una meteórica carrera en ascenso por los títulos publicados hasta hoy con el esencial objetivo de motivar a la lectura desde edades tempranas e instruir en habilidades cotidianas utilizando la transversalidad en la Literatura infantil.

Entre sus obras destacan Los despistes del abuelo (2012), Hijito Pollito (2012), Papá monstruo (2015) y Los dientes de Trino Rojo (2017). Las camisetas no somos servilletas (2019) ${ }^{I}$ (T-shirts Aren't Napkins) es, hasta el momento, su último libro publicado, un álbum ilustrado por la napolitana Martina Peluso con el que ha obtenido en 2020 una mención de honor -de las tres otorgadas- en los Latino Book Awards de Estados Unidos. Medalla de Plata concedida a escritores latinos de libros con formato bilingüe, en el caso de nuestra escritora, afincada en Molina de Segura, las lenguas han sido la castellana y la inglesa. Se trata de un premio con el que en ediciones anteriores se alzaron nombres tan prestigiosos como Isabel Allende o el premio nobel Mario Vargas Llosa. Es exactamente en Nueva York donde tiene lugar la mayor feria del libro infantil y donde se celebra la ceremonia de entrega del galardón, lo que implica una importante promoción y distribución del libro de la murciana. Con anterioridad, los dos primeros títulos referidos fueron premiados en Estados Unidos en los años 2012 y 2013, respectivamente, en sus versiones inglesas en los Moonbeam Children's Book Awards.

Marta Zafrilla aúna en toda su cuentística su condición de profesora y de madre de dos hijos (del también escritor Rubén Castillo). Por ello, de manera atinada, utiliza como elementos básicos en sus cuentos el amor y el humor, las mejores herramientas

\footnotetext{
${ }^{1}$ Marta Zafrilla Díaz, Las camisetas no somos servilletas, Madrid, Cuento de luz, 2019.
} 
para una literatura beneficiosamente provechosa. Es plenamente consciente de que entre los cuatro y nueve años los intereses lectores varían progresivamente desde las canciones y narraciones con animales, pasando después a aquellos relatos que respondan a sus porqués hasta sentirse muy atraídos (hacia los nueve años y antes de los doce) por novelas cortas humorísticas. Así leemos en títulos como Hijito pollito (Little Chick) la trama de una cría avícola cuidada por una gata. Pudiera parecer, a bote pronto, una patraña incoherente, aunque esté protagonizada por animales dotados de la facultad de hablar; sin embargo, la interpretación va más allá porque la lectura -en voz alta, mejor- presenta patrones de conducta, prototipos de comportamiento, a los que el lector infantil debe aspirar. La diversidad en edades primigenias y los derechos del niño, tales como el derecho a una familia, toman específica relevancia.

En «Los despistes del abuelo Pedro» («The mistakes of grandfather Pedro») la estereotipada pareja de un abuelo y su nieto nos conduce por los vericuetos de esa cruel enfermedad que es el alzhéimer y, entre la tristeza y el disparate, la autora sensibiliza sobre ella.

«Los dientes de Trino Rojo» («Red trill teeth») es otro de los cuentos en el que con una prosa fluida, un lenguaje sencillo y una historia amena, se aborda la enseñanza de la higiene bucal. Lee el iniciático lector fragmentos como: «Preguntando a Pez Dorado averiguó que los tiburones se limpian todos sus afilados dientes con algas (¡tienen varias filas de ellos! ¡Deben de tardar muchísimo en dejarlos relucientes!)» (Zafrilla, 2017: 3).

La creatividad de esta escritora encierra en sus páginas junto a una potente imaginación, la plausible pretensión de instruir. Así pues, la historia contada en sus narraciones cortas se convierte en el canal apropiado para transmitir un heterogéneo repertorio de valores educativos pertenecientes tanto al entorno académico como al doméstico. Tareas y hábitos forman un tándem unido, unas y otros se combinan con juegos propuestos en lo que desde antaño se ha conocido como la literatura lúdica y que ahora es remozada por esta escritora, que cree que «gracias a los libros, el juego y la imaginación, la mente del niño se agranda, y este tiene más posibilidades de ser flexible ante el mundo» ${ }^{2}$.

Todos los cuentos están escritos con el envoltorio de la naturalidad y la expresividad lingüística, al más puro estilo de Marta Zafrilla. La narradora orienta su discurso mediante un lenguaje respetuoso, visual y accesible al acervo de sus receptores, los párvulos, quienes, además de protagonistas de las líneas de Zafrilla, son, también a la vez, los destinatarios inmediatos de sus mensajes literales y metafóricos. Otra propiedad percibida reside en la oralidad con que puede ser transmitida esta serie de

\footnotetext{
${ }^{2}$ Rosa Martínez, «Marta Zafrilla: “La perfección no existe”», La Verdad, en https://www.laverdad.es/ culturas/libros/perfeccion-existe-20190422003802-ntvo.html (22 de abril de 2019).
} 
cuentos, una oralidad actualizada, dadora de un ritmo vivo, ágil, dinámico y acentuada a través de potenciadores de voz, interpretación de canciones, efectos sonoros, músicas de preferencia estética, etc. La canción, un recurso ancestral manejado con frecuencia como instrumento didáctico, es incluso interpretada por la propia artífice de lo escrito. Constancia queda de ello en prensa y en las presentaciones públicas efectuadas (sin duda, interesante tema de investigación). Viene a convertirse la canción en un refrendo del tema principal del relato. Así ocurre, por ejemplo, en Las camisetas no somos servilletas: «A lavarse las manos, / a lavarse las manos, / por delante, por detrás, / entre los dedos y una vez más. A lavarse las manos, / a lavarse las manos. / Por delante, por detrás, / entre los dedos. / ¡Lo hago genial!»»3.

Este novedoso enfoque concedido por Marta Zafrilla al cuento encuentra su publicación en una innovadora forma de impresión utilizando el papel de piedra o papel mineral, que no requiere tala de árboles ni de agua, cloro u otros productos químicos.

Para concluir, solo nos resta añadir, junto a su estimación literaria, su consideración de libros pedagógicos veteados de ternura, lenidad y dulzura.

${ }^{3}$ Evelyn Piñero, Feliz Día Internacional del Libro con la escritora molinense Marta Zafrilla, en http:// radiomolina.com/podcast/feliz-dia-internacional-del-libro-con-la-escritora-molinense-marta-zafrilla/ (2020, 23 de abril). 